Https://online.unisc.br/seer/index.php/cadpesquisa

ISSN on-line: $1677-5600$

Doi: $10.17058 / c p . v 30 i 1.12196$

Universidade de Santa cruz do Sul - Unisc

Autor para contato: lobo@unisc.br

\title{
Avaliação da qualidade da água de nascentes da Bacia do Arroio Andréas, RS, Brasil, com base em ensaios ecotoxicológicos e genotoxicológicos com Daphnia magna (Straus, 1820)
}

\author{
Evaluation of the water quality in the Andreas Stream Hydrographic Basin, RS, Brazil, based on \\ ecotoxicological and genotoxicological assays with Daphnia magna (Straus, 1820)
}

\author{
Daiane Cristina de Moura \\ Francisco Moraes Taques \\ Alexandre Rieger \\ Eduardo Alexis Lobo \\ Universidade de Santa Cruz do Sul - UNISC - Santa Cruz do Sul - Rio Grande do Sul - Brasil
}

\section{Resumo}

A avaliação convencional da qualidade da água é realizada medindo variáveis físico-químicas e microbiológicas, no entanto outras metodologias podem ser empregadas, como ensaios de ecotoxicidade e genotoxicidade. Assim, esta pesquisa objetivou avaliar a qualidade da água de nascentes da Bacia do Andréas, RS, utilizando o enfoque convencional, bem como ensaios ecotoxicológicos e genotoxicológicos, usando o Ensaio Cometa (EC) com o organismo-teste Daphnia magna. Foram avaliadas amostras de água de 19 nascentes na bacia, em setembro de 2015. As variáveis medidas foram: temperatura, $\mathrm{pH}$, turbidez, oxigênio dissolvido, demanda bioquímica de oxigênio, nitratos, fosfato, sólidos totais dissolvidos e coliformes termotolerantes. $\mathrm{O}$ teste ecotoxicológico seguiu a norma brasileira NBR-12713, e para o teste genotoxicológico, aplicou-se o EC. Comparações foram feitas utilizando a prova estatística de Mann-Whitney com $\alpha=5 \%$. Os resultados ecotoxicológicos indicaram que nenhuma amostra foi classificada como tóxica, enquanto que os genotoxicológicos indicaram toxicidade em $47,4 \%$ das amostras. Entretanto, considerando as análises convencionais, essas amostras foram classificadas como classes de uso 1 ou 2 do CONAMA, resolução 357/2005, consideradas de boa qualidade. Esses resultados destacam a importância de testes genotoxicológicos como ferramenta complementar na avaliação da qualidade da água, já que detecta alterações mesmo em águas consideradas de boa qualidade.

\section{Abstract}

Conventional water quality evaluation is made by measuring physico-chemical and microbiological variables; however, other methodologies may be employed, such as ecotoxicity and genotoxicity assays. Thus, this study aimed at evaluating the water quality in headsprings in the Andreas Basin, RS, using the conventional approach, as well as ecotoxicological and genotoxicological tests, using the Comet Assay (EC) with the test-organism Daphnia magna. Water samples from 19 springs in the basin were evaluated, in September 2015. The variables measured were: temperature, $\mathrm{pH}$, turbidity, dissolved oxygen, biochemical oxygen demand, nitrate, phosphate, dissolved total solids and faecal coliforms. The ecotoxicological test with D. magna followed the Brazilian standard NBR-12713, while for genotoxicity test; the EC was applied. Comparisons were made using the statistical Mann-Whitney test with $\alpha=5 \%$. The ecotoxicological results indicate that no samples were classified as toxic, instead the genotoxicological ones indicated genotoxicity in $47.4 \%$ of the samples. However, considering the results of the conventional analyzes, these samples were classified as use classes 1 or 2 of CONAMA, resolution 357/2005, being considered of good quality. These results highlight the importance of the use of genotoxicological tests as a complementary tool for evaluating water quality, since it detects alterations even in waters considered of good quality.

\section{Palavras-chave}

Teste Ecotoxicológico. Ensaio Cometa. Daphnia magna. Bacia do Arroio Andreas, RS.

\section{Keywords}

Ecotoxicological test. Comet Assay. Daphnia magna. Andreas Hydrographic Basin,

RS. 


\section{Introdução}

A água é um recurso natural imprenscindível à vida de todos os seres vivos, entretanto, sofre variados impactos negativos resultantes das atividades humanas, como acontece na Bacia do Arroio Andreas. Localizada no município de Vera Cruz, RS, área tipicamente agrícola, o Arroio Andreas recebe por lixiviação fertilizantes e agroquímicos empregados nas lavouras ao entorno (MOURA et al., 2017).

Assim, a avaliação da qualidade da água é de extrema importância, sendo comumente utilizadas variáveis físicas, químicas e microbiológicas, porém outros testes podem ser empregados, como os testes de toxicidade, com destaque para a utilização de bioindicadores na avaliação da qualidade da água como, por exemplo, o uso do microcrustáceo Daphnia magna (STRAUS, 1820), popularmente chamado de "pulga d'água", comumente utilizado em ensaios ecotoxicológicos para avaliação de impactos ambientais, nos quais se testam os impactos potencialmente deletérios de substâncias ou compostos químicos que agem como poluentes sobre os organismos vivos, possibilitando a definição de padrões de qualidade da água (LOBO, RATHKE e BRENTANO, 2006).

Cabe destacar, entretanto, que outros testes podem ser empregados a fim de complementar os dados obtidos pelos testes ecotoxicológicos, como os ensaios genotoxicológicos, com destaque para o Ensaio Cometa (EC), teste que vem se mostrando uma importante ferramenta uma vez que detecta alterações no material genético passíveis de reparo, e que não afetam a viabilidade nem a vitalidade do organismo teste, ou seja, capaz de detectar alterações antes mesmo que essas causem a mortalidade dos seres vivos em estudo (MOURA et al., 2017).

Neste contexto, a presente pesquisa objetivou avaliar a qualidade da água de nascentes da Bacia Hidrográfica do Arroio Andréas, RS, utilizando o enfoque convencional físico, químico e microbiológico, bem como ensaios ecotoxicológicos e genotoxicológicos, usando o Ensaio Cometa (EC) com o organismo-teste Daphnia magna.

\section{Material e métodos}

\section{Área de estudo/amostragem}

Em setembro de 2015 realizaram-se coletas da água em 19 nascentes localizadas em áreas de proteção de recurso hídricos na Bacia Hidrográfica do Arroio Andréas, localizada no município de Vera Cruz, RS (Fig. 1).

\section{Daphnia magna}

Para a realização dos ensaios ecotoxicológicos e genotoxicológicos, neonatos de $D$. magna (Fig. 2) foram cultivados de acordo com a norma técnica brasileira 12713 (ABNT, 2009). Para este propósito, indivíduos adultos foram mantidos em água reconstituída com fotoperíodo de 16 horas luz e 8 horas escura, a uma temperatura de $20^{\circ} \mathrm{C} \pm 2{ }^{\circ} \mathrm{C}$; sendo alimentados diariamente com algas da espécie Desmodesmus subspicatus.

Posteriormente, uma parte do lote de neonatos foi submetida a um teste de sensibilidade com Dicromato de Potássio, que indicou se o cultivo de $D$. magna estava apto para a utilização em ensaios. Após os neonatos foram empregados nos testes ecotoxicológicos e genotoxicológicos, com idade entre 2 a 26 horas. Utilizou-se um Controle Negativo (CN) composto por água reconstituída. 


\section{Testes ecotoxicológicos com Daphnia magna}

Os testes ecotoxicológicos com $D$. magna foram realizados em duplicata, consistindo na exposição aguda de 10 indivíduos em $25 \mathrm{ml}$ da amostra. Após 48 horas de exposição realizou-se o levantamento de indivíduos sobreviventes. $O$ grau de toxicidade foi calculado com base na norma 12713 (ABNT, 2009), que classifica uma amostra como não tóxica quando apresenta uma taxa de sobrevivência superior a $80 \%$.

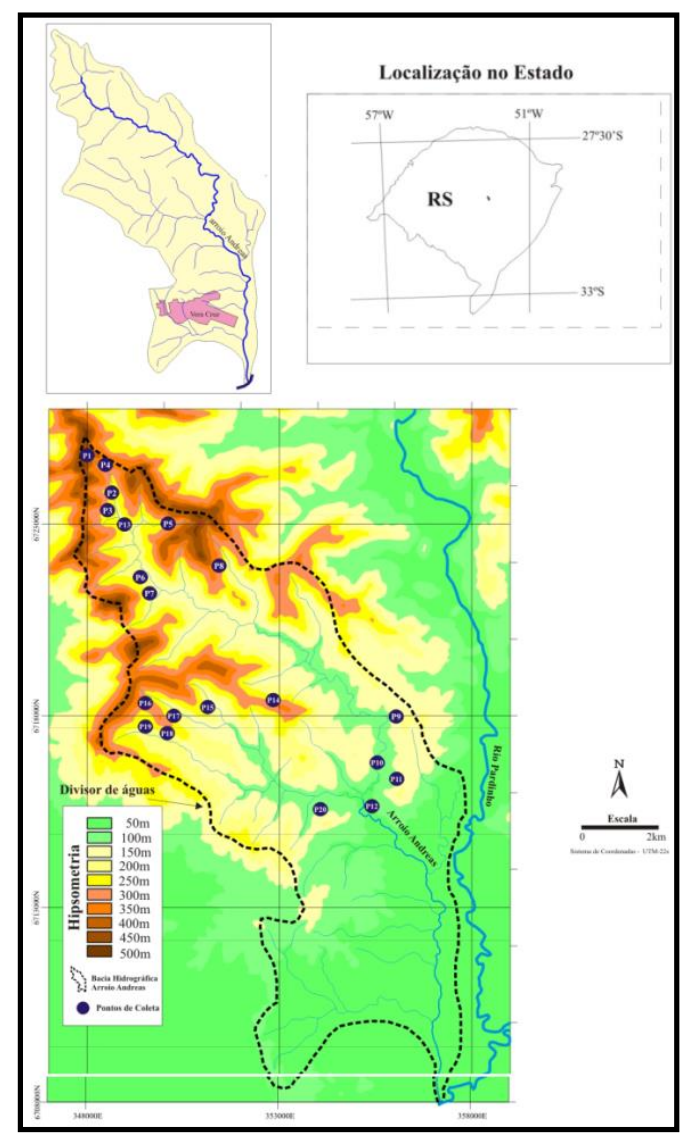

Figura 1. Mapa da área de estudo mostrando a localização da bacia do Arroio Andréas, em relação ao Estado do Rio Grande do Sul, destacando os pontos de coleta selecionados.

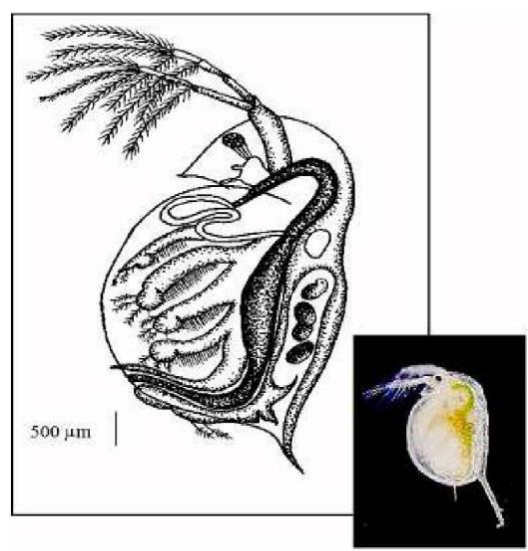

Figura 2. Representação de Daphnia magna. 


\section{Testes genotoxicológicos com Daphnia magna}

Para a realização do teste genotoxicológico utilizou-se o Ensaio Cometa (EC), realizado em sequência à exposição aguda de $D$. magna, com base no trabalho de Park e Choi (2007) e Zenkner et al. (2012). Os neonatos foram transferidos com o auxílio de pipetador automático e armazenados em solução contendo $850 \mu \mathrm{l}$ de tampão fosfato salino (PBS com pH 7,4), $20 \mathrm{mM}$ de ácido etileno diamino tetra-acético (EDTA) e $50 \mu \mathrm{l}$ de Dimetilsulfóxido (DMSO). Posteriormente o material foi macerado e centrifugado por 10 minutos, a uma temperatura de $4^{\circ} \mathrm{C}$ e a velocidade de $2.100 \mathrm{rpm}$, com descarte do sobrenadante. 0 material foi exposto em 5 lâminas pré-cobertas e acrescido de agarose, sendo $20 u \underline{L}$ de material e 80 ųL de agarose de baixo ponto de fusão a $1,5 \%$, mantida aquecida a $37{ }^{\circ} \mathrm{C}$.

A suspensão celular juntamente com a agarose foi disposta sobre a lâmina e recoberta por lamínula. Após refrigeração, removeram-se as lamínulas e as lâminas foram submetidas a uma solução de lise por 1 hora. A solução de lise é composta de 2,5 M NaCl, $100 \mathrm{mM}$ Na2EDTA e $10 \mathrm{mM}$ TRIS, com pH 10. No momento de uso adicionou-se $1 \%$ Triton X-100, e 10\% DMSO. Inicia-se a eletroforese alcalina $(\mathrm{pH}>12)$, onde as lâminas foram submersas durante 15 minutos em tampão eletroforese para desnovelamento do DNA. A seguir, deu-se seguimento a eletroforese $(0,7 \mathrm{~V} / \mathrm{cm} ; 300 \mathrm{~mA})$ com duração de 20 minutos. Terminada a eletroforese as lâminas foram neutralizadas (Tris $0,4 \mathrm{M}$ ), lavadas com água destilada e postas para secar naturalmente. Após foram fixadas e secas novamente, para receberem a coloração a base de nitrato de prata.

No processo de coloração, as lâminas foram reidratadas com água destilada, e posteriormente submersas em uma solução a base de nitrato de prata para que ganhassem cor, foram acondicionadas em shaker com agitação de 120 RPM, a 37으 por 35 minutos, seguindo a metodologia descrita em Nadin, Vargas-Roig e Ciocca (2001). Após o processo de coloração as lâminas foram então analisadas em microscopia óptica convencional (aumento de 400x), onde para cada lâmina se contabilizou 100 nucleóides, totalizando 500 nucleóides por amostra. Os nucleóides foram classificados em 5 tipos de danos (0, 1, 2, 3 e 4), quanto maior 0 dano maior o dígito correspondente, sendo a classe 0 destinada para nucleóides livres de dano (Fig. 3).

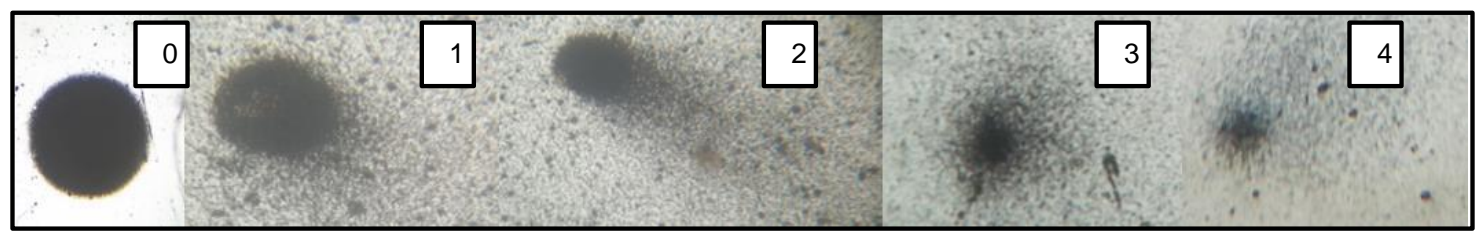

Figura 3. Classes de Danos dos nucleóides. Em sequência nucleóides de dano 0, 1, 2, 3 e 4 (aumento de 400x).

Com a classificação dos nucleóides obteve-se dois tipos de informações, o Índice de Dano (ID) e a Frequência de Dano (FD), ambos comparados ao Controle Negativo (CN) do teste. O ID corresponde ao total do resultado da multiplicação entre o dígito denominador de cada classe $(0,1,2,3$ e 4$)$ e o número de nucleóides de cada classe. Já a FD é calculada como a porcentagem de todos os nucleóides danificados (classe 1 até 4) em relação ao total de nucleóides contados.

Os valores de FD e ID foram estandartizados em relação à respectiva média do grupo CN. O valor padronizado foi obtido pela razão entre a FD (ou ID) de cada amostra pela respectiva FD (ou ID) da média do grupo CN de cada teste. No processamento da informação, empregou-se a estatística descritiva para a tabulação dos dados (CALLEGARI-JACQUES, 2006). As diferenças estatísticas foram estabelecidas utilizando a prova estatística não paramétrica de 
Mann-Whitney. Trabalhou-se com níveis de significância de $5 \%(p<0,05)$. As análises foram processadas utilizando-se o programa estatístico GraphPad Prism6.01 (GraphPad, 2012).

\section{Testes Convencionais}

As amostras foram coletadas na superfície utilizando-se frascos de vidro, acondicionadas em caixa de isopor contendo gelo e analisadas no dia seguinte à coleta. As técnicas utilizadas na coleta das amostras bem como as determinações físicas e químicas realizadas encontram-se descritas em APHA (2005). As variáveis medidas foram ase seguintes: temperatura, pH, turbidez, oxigênio dissolvido, demanda bioquímica de oxigênio, nitratos, fosfato, sólidos totais dissolvidos e coliformes termotolerantes.

A partir dos resultados obtidos, os 19 pontos de amostragem foram classificados quanto à qualidade da água segundo a resolução 357 do Conselho Nacional do Meio Ambiente (CONAMA) de 2005 (BRASIL, 2005), que dispõe sobre a classificação dos corpos de água e diretrizes ambientais para o seu enquadramento, classificando as águas doces em cinco classes diferentes, em função dos usos a que se destinam (Tab. 1).

Tabela 1. Classificação de águas doces em função dos usos (BRASIL, 2005).

\begin{tabular}{|c|c|}
\hline Classe & Águas que podem ser destinadas \\
\hline Especial & $\begin{array}{l}\text { ao abastecimento para consumo humano, com desinfecção; } \\
\text { à preservação do equilíbrio natural das comunidades aquáticas; e, } \\
\text { à preservação dos ambientes aquáticos em unidades de conservação de proteção } \\
\text { integral. }\end{array}$ \\
\hline Classe 1 & $\begin{array}{l}\text { ao abastecimento para consumo humano, após tratamento simplificado; } \\
\text { à proteção das comunidades aquáticas; } \\
\text { à recreação de contato primário, tais como natação, esqui aquático e mergulho, } \\
\text { conforme } \\
\text { Resolução CONAMA } n^{\circ} 274 \text {, de } 2000 \text {; } \\
\text { à irrigação de hortaliças que são consumidas cruas e de frutas que se } \\
\text { desenvolvam rentes } \\
\text { ao solo e que sejam ingeridas cruas sem remoção de película; e } \\
\text { à proteção das comunidades aquáticas em Terras Indígenas. }\end{array}$ \\
\hline Classe 2 & $\begin{array}{l}\text { ao abastecimento para consumo humano, após tratamento convencional; } \\
\text { à proteção das comunidades aquáticas; } \\
\text { à recreação de contato primário, tais como natação, esqui aquático e mergulho, } \\
\text { conforme } \\
\text { Resolução CONAMA no 274, de 2000; } \\
\text { à irrigação de hortaliças, plantas frutíferas e de parques, jardins, campos de } \\
\text { esporte e } \\
\text { lazer, com os quais o público possa vir a ter contato direto; e } \\
\text { à aqüicultura e à atividade de pesca. }\end{array}$ \\
\hline Classe 3 & $\begin{array}{l}\text { ao abastecimento para consumo humano, após tratamento convencional ou } \\
\text { avançado; } \\
\text { à irrigação de culturas arbóreas, cerealíferas e forrageiras; } \\
\text { à pesca amadora; } \\
\text { à recreação de contato secundário; e } \\
\text { à dessedentação de animais. }\end{array}$ \\
\hline Class & $\begin{array}{l}\text { à navegação; e } \\
\text { à harmonia paisagística. }\end{array}$ \\
\hline
\end{tabular}




\section{Resultados e discussões}

\section{Testes ecotoxicológicos}

No teste ecotoxicológico com exposição aguda (48h) de D. magna (20 indivíduos/amostra) encontrou-se mortalidade em $31,6 \%$ das amostras, contudo, em todas elas a sobrevivência foi superior a $80 \%$, sendo classificadas como amostras "não tóxicas" seguindo a norma brasileira ABNT 12713 (ABNT, 2009). Desta forma, os resultados indicaram que do ponto de vista ecotoxicológico, nenhuma amostra foi enquadrada como tóxica.

\section{Testes genotoxicológicos}

Os testes genotoxicológicos realizados através do EC em $D$. magna revelam genotoxicidade para algumas amostras, tanto para FD quanto para ID (Tab. 2). Observa-se que as amostras P1, P2, P3, P5, P6, P7, P9 e P10, foram capazes de gerar alterações ao material genético do organismo-teste, tanto em FD como para ID, além de P19 somente para ID. Levando em consideração apenas os valores da FD de cada amostra e comparando os mesmos com a FD do $\mathrm{CN}$, verifica-se que P10 apresentou a maior resposta genotoxicológica (2,5 vezes maior). Em relação ao ID, a amostra com diferença mais relevante em comparação ao $\mathrm{CN}$ foi P19 (5 vezes maior).

\section{Análises Convencionais}

A partir das determinações das análises físicas, químicas e microbiológicas, as amostras foram classificadas utilizando a resolução $n^{\circ} 357 / 2005$ do CONAMA (BRASIL, 2005), destacando que das 19 amostras, 68,4\% (13) foram enquadradas na Classe de uso 1 e 26,3\% (5) na Classe de uso 2 do CONAMA, consideradas águas de boa qualidade. Apenas uma amostra (P16) apresentou classe de uso 3 do CONAMA, considerada como regular, no entanto, esta amostra não apresentou toxicidade nem para os testes ecotoxicológicos nem para os testes genotoxicológicos.

Observa-se que enquanto a ecotoxicidade aguda não enquadrou nenhuma amostra como tóxica, o Ensaio Cometa encontrou genotoxicidade em P1, P2, P3, P5, P6, P7, P9, P10 e $\mathrm{P} 19$. Assim, as diferenças de toxicidade encontradas relacionam-se com o fato descrito por Palma et al. (2016), uma vez que o ensaio agudo é dependente da presença de concentrações suficientemente elevadas, que comprometem a sobrevivência do organismo. Ao contrario dos testes genotoxicológicos que fazem uso do EC, uma vez que apresenta sensibilidade na detecção de lesões mesmo em organismos expostos a baixas concentrações de toxinas (PRÁ et al., 2005).

Os resultados apontaram, também, diferenças entre os testes genotoxicológicos e os testes convencionais, visto que pelas análises genotoxicológicas $47,4 \%$ dos pontos amostrados foram considerados tóxicos, enquanto que pelas análises convencionais, todos estes pontos foram classificados como classes de uso 1 ou 2 do CONAMA (Conselho Nacional do Meio Ambiente), consideradas de boa qualidade.

Esses resultados ressaltam a importância da utilização de ensaios genotoxicológicos como ferramentas complementares às análises convencionais de avaliação da qualidade da água, uma vez que os parâmetros levados em consideração para a determinação da qualidade da água pelas análises convencionais não constituem um fator genotóxico. De fato, Babić et al. (2017) concluíram que testes genotoxicológicos são uma ferramenta útil no monitoramento de toxicidade de ecossistemas aquáticos em geral, complemetando às análises convencionais. 
Tabela 2. Resultados de FD (Frequência de Dano) e ID (Índice de Dano) em D. magna referente ao Controle Negativo (CN) e aos pontos amostrados.

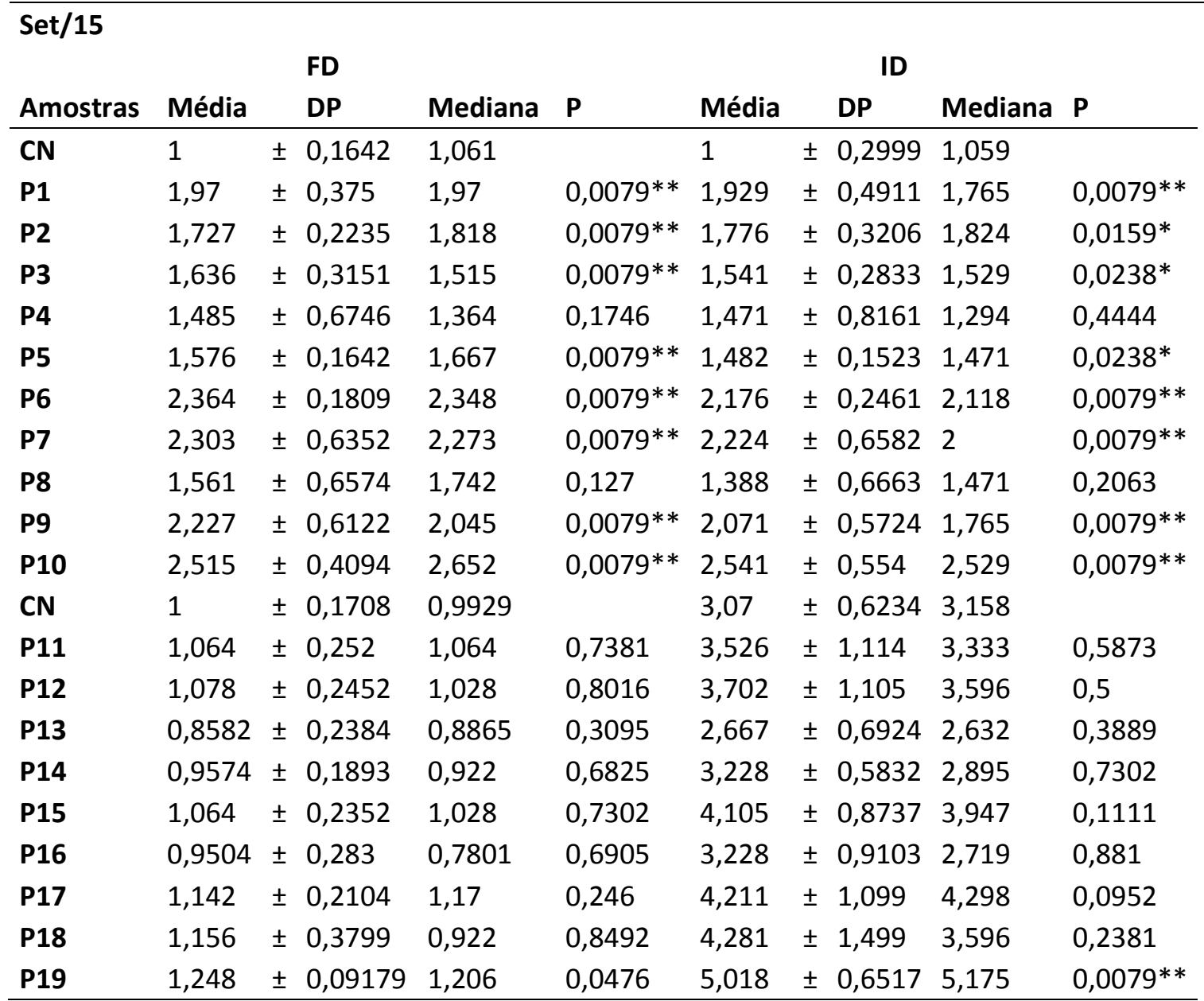

Utilizou-se o teste de Mann-Whitney, comparando cada amostra contra o CN ( ${ }^{*} p<0,05$; $* * p<0,01)$.

A genotoxicidade observada poderia ser explicada considerando a lixiviação de insumos agrícolas empregados em lavouras próximas aos pontos de coleta amostrados. De fato, Vera Cruz tem sua agricultura baseada no cultivo de tabaco (SILVEIRA, 2015), cultura caracterizada pelo uso intensivo de agrotóxicos para o combate a pragas, controle de doenças e otimização da produção (GOULART e CALLISTO, 2003; TORRES, 2006; VALE, 2016). Ainda, em setembro, época de coleta das amostras, as lavouras de tabaco recebem o transplante das mudas de fumo, que compreende o preparo do solo com a adubação, química e orgânica (esterco) e uma aplicação de agrotóxicos. Vários dados experimentais revelaram que muitas destas substâncias podem induzir alterações cromossômicas, mutações e danos ao DNA ou às proteínas de sua estrutura em organismos vivos (GARAJ-VRHOVAC e ZELJEZIC, 2001).

\section{Referências}

1. ABNT - ASSOCIAÇÃO BRASILEIRA DE NORMAS TÉCNICAS. NBR 12713: Ecotoxicologia aquática - Toxicidade aguda - Método de ensaio com Daphnia spp. (Cladócera, Crustácea). 3. ed. São Paulo, 2009.

2. APHA. American Public Health Association. Standard Methods for the Examination of water and Wastewater. 21 ed. Washington. 2005. 
3. BABIĆ S.: BARIŠIĆ J.; VIŠIĆ H,; KLOBUČAR S.R.; POPOVIĆ, T.N.; STRUNJAK-PEROVIĆ, I.; ČOŽ-RAKOVAC, R.; KLOBUČAR, G. Embryotoxic and genotoxic effects of sewage effluents in zebrafish embryo using multiple endpoint testing. Water Research, v. 115, p. 9-21, 2017.

4. BRASIL. Conselho Nacional do Meio Ambiente. Resolução n. 357, de 17 de março de 2005. Diário Oficial da República Federativa do Brasil, Brasília, DF, 18 de março de 2005. 2005. Disponível em: <http://www.mma.gov.br/port/CONAMA/res/res05/res35705.pdf>.

5. CALLEGARI-JACQUES, S. D. Bioestatística. Princípios e Aplicações. Porto Alegre: Artmed. 255p. 2006.

6. GARAJ-VRHOVAC, V.: ZELJEZIC, D. Cytogenetic monitoring of Croatian population occupationally exposed to a complex mixture of pesticides. Toxicology, v. 165, p. 153162, 2001.

7. GOULART, M.; CALLISTO, M. Bioindicadores de qualidade de água como ferramenta em estudos de impacto ambiental. Revista da FEPAM, v. 2, n. 1, p. 153-164, 2003.

8. GraphPad, 2012. Instat guide to choosing and interpreting statistical tests. San Diego, Ca (http//www.graphpad.com).

9. LOBO, E.A.; RATHKE, F.S.; BRENTANO, D.M. Ecotoxicologia aplicada: o caso dos produtores de tabaco na Bacia Hidrográfica do Rio Pardinho, RS, Brasil. p. 41-68. In: ETGES, V. E.; FERREIRA, M.A.F. A produção do tabaco: impacto no ecossistema e na saúde humana na região de Santa Cruz do Sul/RS. Santa Cruz do Sul: EDINISC, 248p. 2006.

10. MOURA, D.C., SOUSA, C.M.M., RIEGER, A., LOBO, E.A. Avaliação da qualidade da água de nascentes na Bacia do Arroio Andréas, RS, Brasil, através de ensaios ecotoxicológicos e gentoxicológicos utilizando o Ensaio Cometa. In.: VIERA, V.B.; PIOVESAN, N. Biotecnologia: Aplicação Tecnológica nas Ciências Agrárias e Ambientais, Ciência dos Alimentos e Saúde, 2017.

11. NADIN S. B.; VARGAS-ROIG L. M.; CIOCCA D. R. A silver staining method for single-cell gel assay. The Journal of Histochemistry \& Cytochemistry, v. 49, n. 9, p. 1183-1186, 2001.

12. PALMA, P., LEDO, L.; ALVARENGA, P. Ecotoxicological endpoints, are they useful tools to support ecological status assessment in strongly modified water bodies? Science of the Total Environment, v. 541, p. 119-129, 2016.

13. PARK, S. Y.; $\mathrm{CHOI}$, J. Cytotoxicity, genotoxicity and assay using human cell and environmental species for the screening of the risk from pollutant exposure. Environmental International, v.33, p. 817-822, 2007.

14. PRA, D., LAU, A.H., KNAKIEVICZ, T., CARNEIRO, F.R., ERDTMANN, B. Environmental genotoxicity assessment of an urban stream using freshwater planarians. Mutation Research, v. 585, n. 1-2, p. 79-85, 2005. 
15. SILVEIRA, R.L. A cultura do tabaco na Região Sul do Brasil: dinâmica de produção, organização espacial e características socioeconômicas. Geografia Ensino \& Pesquisa, v. 19, n. 2, p. 23-40, 2015.

16. TORRES, J.M. Aspectos Ambientais da Produção de Tabaco em Santa Cruz do Sul, Sinimbu e Gramado Xavier. p. 69-90. In: ETGES, V. E.; FERREIRA, M.A.F. A produção do tabaco: impacto no ecossistema e na saúde humana na região de Santa Cruz do Sul/RS. Santa Cruz do Sul: EDINISC, 248p. 2006.

17. VALE, A. In: Proteção Contra Agrotóxicos - CIPA. v. 38, n.438, 2016.

18. ZENKNER, F.F.; ATHANASIO, C. .; ELLWANGER, J.H.; PRÁ, D.; RIEGER, A.; LOBO, E.A. Análise genotóxica de efluente de lavanderia hospitalar: Ensaio Cometa com Daphnia magna Straus, 1820. Revista Jovens Pesquisadores, n. 1, p. 29-36, 2012. 